\title{
PEMANFAATAN LIMBAH POPOK SEBAGAI SARANA PENDIDIKAN KARAKTER PEDULI LINGKUNGAN ANAK USIA DINI
}

\author{
Talitha Widiatningrum $^{1}$, Krispinus Kedati Pukan ${ }^{2}$, R. Susanti, Sri Sukaesih ${ }^{3}$ \\ ${ }_{1,2,3}$ Pascasarjana Universitas Negeri Semarang
}

\begin{abstract}
TK Wiji is a nursery school which was built at Jl. Untung Suropati no. 10 kelurahan Tegalrejo kota Pekalongan based on NPSN 69879295 of 2005 by Yayasan 99. TK Wiji is growing fast due to its education system which is in line to the 2013 national curriculum with the vision of toodler characteristic development. The most fundamental of character education is environment education. Considering to this situation, we have found that the most common litter of the nursery is disposable diaper. This kind of diaper is hardly degraded into its monomer. Colon's research in 2013 has found a strategy to use this diaper as compost. Based on the problem of disposable diaper wastes in the nursery and also the result of the background research about exploiting the waste as compost, then the environment education for toodler of TK Wiji by using diaper waste as a material for hidroponic cultivation was done. In the beginning, guidances were given to the teacher in 2 phases which are making diaper waste composite into organic fertilizer and making hidrogel for interior plant cultivation by using the gel of the waste. In the next step, the teachers were asked to make improvisation regarding toodler environment education by using the skills. In spite of this, there was still an argument about the time management in the learning process by using diaper waste as the material. Thus an implementation of the skill for toodler extracuricular was stated.
\end{abstract}

Keywords: Diaper Waste, Environment Education, Toodler, Hidroponic, Hidrogel 


\begin{abstract}
Abstrak
TK Wiji adalah tempat pendidikan anak usia dini di Jl. Untung Suropati no. 10 kelurahan Tegalrejo kota Pekalongan yang didirikan dengan NPSN 69879295 pada tahun 2005 oleh Yayasan 99. TK Wiji tumbuh dengan pesat karena memiliki sistem pendidikan yang sesuai dengan kurikulum nasional 2013 bervisi pembentukan karakter anak. Pendidikan karakter paling dasar adalah pendidikan lingkungan. Terkait dengan hal tersebut, limbah terbanyak yang dihasilkan di TK Wiji adalah limbah popok sekali pakai. Popok bekas yang biasa digunakan siswa adalah disposable diaper yang sukar diurai menjadi monomernya. Penelitian terbaru yang dilakukan oleh Colon pada tahun 2013 berhasil mengolah limbah ini sebagai kompos. Berdasarkan permasalahan yang ditemukan di TK Wiji kelurahan Tegalrejo Pekalongan berupa menumpuknya sampah popok siswa serta dari latar belakang penelitian tentang sampah popok yang dapat difungsikan sebagai pupuk kompos, maka dilakukan pendidikan karakter peduli lingkungan untuk anak usia dini melalui aktivitas pemanfaatan sampah limbah popok sekali pakai sebagai bahan budidaya hidroponik. Awalnya, diberikan pendidikan cara pemanfaatan sampah limbah popok pada guru TK WIJI yang diberikan dalam 2 periode, yaitu membuat campuran pupuk organik berbahan limbah popok sebagai tahap pertama dan membuat hiasan hidrogel dari limbah popok sebagai tahap kedua. Setelah itu, guru diminta untuk melakukan improvisasi pendidikan karakter peduli lingkungan terhadap siswa didiknya dengan sarana belajar pemanfaatan limbah popok. Pada akhir kegiatan, disarankan aplikasi pemanfaatan limbah popok sebagai bahan hidroponik ini bukan hanya sebagai sarana pendidikan tetapi juga sebagai kegiatan ekstrakurikuler yang akan diikuti oleh anak usia dini dengan didampingi orang tua.
\end{abstract}

Kata kunci: Limbah Popok, Pendidikan Lingkungan, Anak Usia Dini, Hidroponik, Hidrogel

\title{
PENDAHULUAN
}

TK Wiji adalah nama dari sebuah tempat pendidikan anak pra sekolah yang terletak di Jl. Untung Suropati no. 10 kelurahan Tegalrejo kota Pekalongan. Sekolah ini merupakan sekolah swasta dengan NPSN 69879295 yang didirikan pada tahun 2005 oleh Yayasan 99 untuk menjawab kebutuhan masyarakat akan pendidikan berkualitas sejak dini, karena secara takdir, manusia sejak lahir selalu berkeinginan untuk mencari kebenaran dan solusi dari segala hal yang dihadapinya. Poin penting untuk dapat melaksanakan pemenuhan kebenaran dan solusi adalah pendidikan. TK Wiji tumbuh dengan pesat karena memiliki sistem pendidikan yang sesuai dengan kurikulum nasional 2013 dengan berbagai pengembangan pola asuh sesuai visi dan misinya, seperti berbasis konservasi dan pembentukan karakter anak (Anonim, 2005). Posisinya yang berada di titik tengah kota Pekalongan dengan biaya pendidikan yang terjangkau, 
dibandingkan dengan letak KB/TK negeri yang cukup jauh dari pusat keramaian, membuat peserta didik yang ingin bergabung di TK Wiji menjadi semakin meningkat dari tahun ke tahun. Hal ini membuat penciptaan iklim sekolah yang seimbang merupakan tantangan yang cukup besar bagi para pendidik. Pembentukan iklim tersebut tentunya harus dimulai dari pembentukan sikap siswa yang dicapai melalui pendidikan karakter.

Pendidikan karakter paling dasar adalah pendidikan lingkungan. Pembentukan sikap mencintai lingkungan yang diiringi dengan sikap menjaga dan melestarikan lingkungan akan membuat siswa berkembang menjadi siswa dengan empati dan norma yang lebih baik. Salah satu pendidikan sikap pelestarian lingkungan adalah pengembangan prinsip 3R, reduce, reuse dan recycle. Prinsip ini berkenaan dengan limbah dan penanganannya yang merupakan hal yang telah menjadi isu nasional. Limbah terbanyak yang dihasilkan di TK Wiji Kelurahan Tegalrejo adalah limbah popok sekali pakai. $50 \%$ dari sekitar 50 orang peserta didik TK Wiji masih menggunakan popok. Setiap pemakai popok yang bersekolah dari pukul 08.00 hingga 10.00 menggunakan minimal 1 buah popok, sementara yang bersekolah dari pukul 08.00 hingga 15.30 menggunakan minimal 2 buah popok. Dengan demikian, minimal terdapat 30 buah popok bekas yang harus dibuang.

Popok bekas yang biasa digunakan siswa adalah disposable diaper. Popok jenis ini antara lain mengandung bahan superabsorbent polymer (Yeong et al, 2014). Bahan popok tersebut, yang kerap disebut SAP, bersifat relatif aman untuk lingkungan karena sukar diurai menjadi monomernya. Jadi pada proses produksi popok, bahan monomer yang beracun dioleh menjadi senyawa kompleks polimer untuk menghilangkan unsur unsur berbahaya didalamnya sekaligus menjadikannya senyawa yang bisa menghisap sejumlah besar air (Buchholz et al, 1998). Popok tersebut umumnya terbuat dari polimer, termasuk selulosa, polypropylene, polyester, dan polietilen (Gambar 3). Bahanbahan ini secara biologis inert dan terpisah dari selulosa, serta tidak bioavailable. Mereka umumnya digunakan dalam kain dan bahan lainnya yang berada dalam kontak dengan kulit, dan dalam makanan dan kosmetik (Dey et al, 2016). 


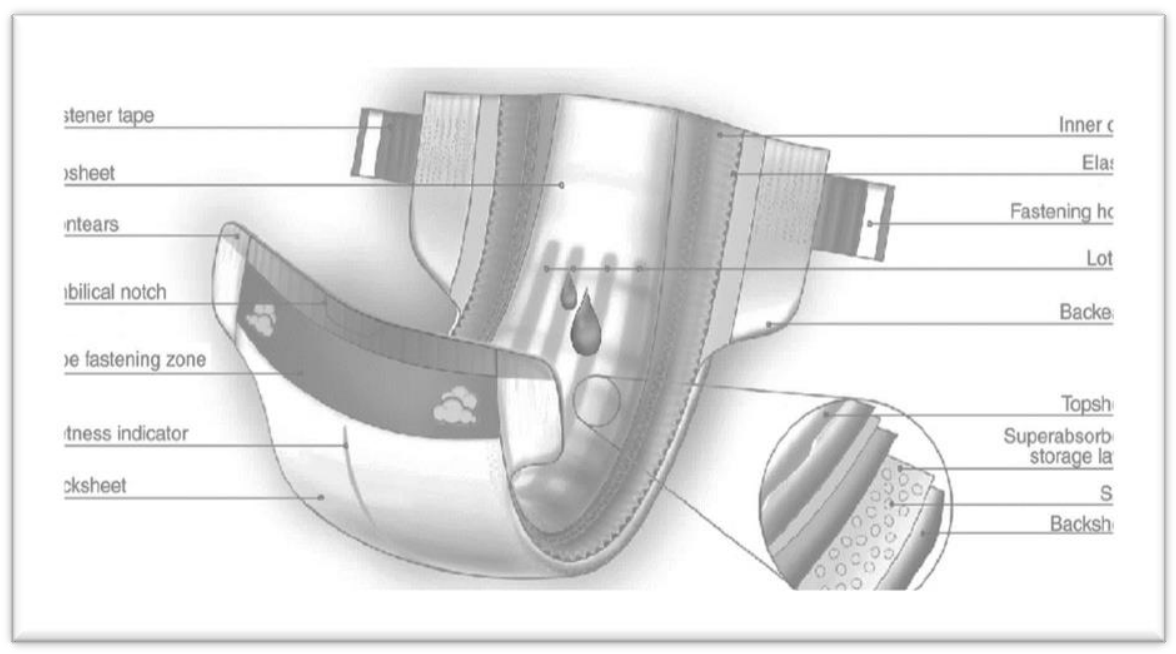

Gambar 3. Struktur material popok disposable (Dey et al, 2016)

Bagian dalam dari popok terbuat dari polimer superabsorben (SAP) yang juga dikenal sebagai gel penyerap. Polimer superabsorben dapat menyerap lebih dari 30 kali beratnya sendiri dalam cairan (Dyer, 2005). Pada saat air kencing bayi memasuki bagian dalam popok, maka ia akan terikat ke SAP dan terkunci. Lebih dari 450 studi keselamatan telah dilakukan untuk mengkonfirmasi keamanan, termasuk penilaian dari endpoint keamanan sistemik dan lokal seperti iritasi kulit atau sensitisasi (Dey et al, 2016). Salah satunya adalah penelitian Buchholz et al (1998) yang menyatakan bahwa bahan SAP, bersifat relatif aman untuk lingkungan karena sukar diurai menjadi monomernya. Jadi pada proses produksi popok, bahan monomer yang beracun dioleh menjadi senyawa kompleks polimer untuk menghilangkan unsur - unsur berbahaya didalamnya sekaligus menjadikannya senyawa yang bisa menghisap sejumlah besar air.

Keamanan dari penggunaan popok disposable sekaligus juga kemudahan dalam pemakainannya membuat kebutuhan akan produk popok sekali pakai semakin hari semakin meningkat. Hal tersebut berdampak pada pencemaran lingkungan dengan adanya penumpukan jumlah sampah bekas pakai. Sampah tersebut merupakan jenis sampah produk yang sulit terurai oleh mikroorganisme sehingga jika dibiarkan akan semakin menumpuk (Rahayu, 2016). Penelitian terbaru yang dilakukan oleh Colon et al (2013) berusaha mengolah limbah yang susah dipecah ini menjadi polimernya sebagai kompos. Usaha pertama yang diterapkan adalah sistem pengumpulan terpisah untuk fraksi organik dari limbah padat perkotaan dan kebutuhan untuk melestarikan lingkungan. Popok non-biodegradable dipisahkan dalam kelompok tersendiri demi menghindari dampak buruk terhadap lingkungan oleh keberadaan popok ini di dalam 
tanah. Dalam penelitian ini, dilakukan percobaan skala laboratorium untuk mengkonfirmasi bahwa hampir 50\% dari karbon kompos pupuk dipancarkan sebagai CO2 dalam kondisi yang terkendali aerobik. Pengembangan skala laboratorium pada skala penuh menunjukkan bahwa kedua proses pengomposan dan produk akhir (kompos) tidak berubah, yang antara lain terdiri dari konten patogen, stabilitas dan komposisi unsur (termasuk nutrisi dan logam berat).

Seiring perkembangan dunia, pertanian lapangan terbuka/berbasis tanah sedang menghadapi beberapa tantangan, terutama karena adanya penurunan ketersediaan lahan kapita. Pada tahun 1960 dengan 3 miliar penduduk didunia, jumlah tanah per kapita adalah 0,5 ha tapi sekarang, dengan 6 miliar penduduk dunia, maka hanya 0,25 ha dan pada tahun 2050, akan mencapai 0,16 ha. Proses urbanisasi yang cepat dan industrialisasi serta mencairnya gunung es (sebagai dampak nyata dari pemanasan global) membuat jumlah tanah subur yang dapat ditanami menjadi menurun. Keadaan seperti itu, jika dibiarkan terus menerus akan menciptakan kemustahilan dalam pemenuhan kebutuhan makan seluruh penduduk yang menggunakan sistem lapangan terbuka produksi pertanian saja. Hal yang dapat dilakukan untuk mengatasi keterbatasan lahan adalah budidaya hidroponik. Istilah hydroponics adalah berasal dari kata Yunani hydro yang berarti air dan ponos yang berarti tenaga kerja. Metode ini menumbuhan tanaman menggunakan larutan mineral nutrisi, tanpa tanah. Kultur hidroponik membuat akar-akar tanaman direndam dalam larutan nutrisi (Sardare dan Admane, 2013).

Budidaya tanaman dapat dilakukan pada media selain tanah. Pemeliharaan tanaman pada media selain tanah ini dikenal dengan hidroponik. Hidroponik, berasal dari kata 'hydro' yang berarti air dan 'ponos' yang berarti kerja, sehingga kultur hidroponik dapat diartikan sebagai kultur dengan media dasar air yang mengandung nutrien. Beberapa penelitian berhasil mengembangkan metode kultur tanpa tanah, yaitu kultur dengan media pasir, kerikil, batu apung, arang, lumut, perlit, vermikulit, sabut kelapa, kulit kayu, potongan kayu, sisa gergajian kayu, sekam, gabus, dan sebagainya dengan tambahan nutrien. Prinsip dari kultur tanpa tanah adalah menggunakan suatu media yang dapat memberikan dukungan mekanis pada tanaman, dengan kondisi oksigen, air dan drainase yang baik. Kultur tanpa tanah selanjutnya digolongkan dalam kelompok kultur hidroponik, sehingga arti kultur hidroponik menjadi luas, yaitu kultur tanaman dengan menggunakan media selain tanah. Salah satu jenis kultur hidroponik 
tersebut adalah akuakultur (Resh, 1998).

Kultur hidroponik mempunyai banyak kelebihan, yang antara lain adalah tidak dibutuhkannya sterilisasi tanah, kualitas tanaman yang dapat diprediksi dengan cara mengatur nutrisi, terhindar dari serangan penyakit, aman bagi lingkungan dan tidak tergantung iklim. Kelebihan tersebut menjadi nilai tambah penerapan kultur hidroponik dalam skala percobaan laboratorium dan produksi tumbuhan skala komersial. Penerapan hidroponik dalam percobaan akan memudahkan pengaturan nutrien dan lingkungan tumbuhan. Dalam skala komersial, aplikasi teknik hidroponik dapat menjadi suatu alternatif produksi skala industri beberapa tumbuhan pangan, terutama di daerah tropis yang merupakan daerah endemis hama dan serangga (Nhut dkk., 2006). Hal-hal yang perlu diperhatikan pada kultur hidroponik antara lain adalah $\mathrm{pH}$ (keasaman), salinitas dan nutrien. Keasaman dapat merubah struktur nutrien. Salinitas berhubungan dengan aktivitas penyerapan air oleh tanaman. Resh (1998) berpendapat bahwa dibandingkan kedua faktor diatas, nutrien adalah faktor yang terpenting dalam kultur hidroponik, karena komposisi nutrien yang tepat dapat mencegah terjadinya defisiensi ataupun surplus nutrien yang akan mengganggu pertumbuhan tanaman.

Suplai air bagi tanaman adalah penting untuk vegetasi. Larutan air menjamin tanaman dapat mengabsorbsi unsur nutrisi dan memberikan dukungan bagi tanaman untuk mendapatkan tingkat pertumbuhan yang lebih baik dengan turgor sel yang baik dan optimal. Hal menarik yang dapat dilakukan berkenaan dengan potensial air adalah dengan mengatur suplai air ini agar dapat mengurangi kehilangan air dan juga memastikan kondisi yang lebih baik bagi vegetasi untuk mempertahankan hidup. Pengaturan ketersediaan air dapat dibantu dengan penggunaan bahan SAP, dengan kemungkinan penerapannya dalam pertanian bidang telah semakin luas diteliti untuk meringankan masalah pertanian tertentu (Zohuriaan-Mehr et al, 1998).

SAP telah berhasil digunakan sebagai pengganti tanah di industri hortikultura untuk meningkatkan sifat fisik tanah dalam meningkatkan kapasitas menahan air dan/ atau retensi hara dari tanah berpasir sebanding dengan tanah liat berlumpur atau lempung. SAP hidrogel berpotensi mempengaruhi permeabilitas tanah, kepadatan, struktur, tekstur, penguapan, dan tingkat infiltrasi air melalui tanah. SAP dalam bentuk hidrogel mampu mengurangi frekuensi irigasi dan kecenderungan pemadatan, menghentikan erosi dan air limpasan, dan meningkatkan aerasi tanah dan aktivitas 
mikroba (Abd El-Rehim et al, 2004).

Kultur hidroponik ini selanjutnya dapat digunakan sebagai salah satu sarana pendidikan. Suatu penelitian tentang evaluasi metode campuran dari kurikulum pembelajaran berbasis taman dalam ruangan yang melibatkan kultur aquaponics dan teknologi hidroponik. Studi ini memberikan pemahaman yang lebih baik tentang sejauh mana teknologi berkebun dalam ruangan dapat digunakan dalam kurikulum formal sebagai alat pengajaran yang efektif. Siswa kelompok perlakuan menunjukkan perbaikan yang signifikan secara statistik pada nilai tes pengetahuan lingkungan serta nilai keseluruhan lebih tinggi pada pelestarian lingkungan, dan dalam beberapa kasus, komitmen untuk berlatih perilaku pro-lingkungan (Jon et al, 2015). Dengan demikian, penanggulangan masalah sampah popok di TK Wiji dengan menerapkan teknologi hidroponik bukan saja mampu menjadi solusi perbaikan kualitas lingkungan tetapi juga dapat menjadi sarana pendidikan yang akan memperbaiki kualitas karakter siswa di TK Wiji Kelurahan Tegalrejo kota Pekalongan.

Analisis situasi lingkungan sekitar terkait kegiatan yang dilakukan memberikan hasil sebagai berikut. Secara fisik, kondisi wilayah sekitar TK Wiji sangat mendukung dilakukannya budidaya hidroponik dengan memanfaatkan popok bekas, karena lokasinya berada di daerah dataran rendah dekat pantai, sehingga ketersediaan air tawar menjadi kurang. Budidaya hidroponik membuat sistem kultur yang memungkinkan tanaman selalu kontak dengan air yang diserap oleh popok, sehingga tidak harus direpotkan dengan usaha mencari air tawar untuk menyiram tanaman. Guru yang menerapkan budidaya juga tidak harus mencari waktu tersendiri disamping kesibukannya dalam mendidik siswa dalam rangka merawat tanaman budidaya yang sedang dikembangkan. Secara sosial, penduduk sekitar TK Wiji terutama yang anaknya menjadi peserta didik TK Wiji memiliki jiwa gotong royong yang tinggi. Para orang tua tidak akan segan untuk turut membantu kesuksesan kegiatan yang diterapkan oleh para guru, seperti kegiatan kultur hidroponik dengan popok ini. Pelatihan yang diadakan nantinya tidak hanya menjadikan guru sebagai sasaran kegiatan, tetapi juga menjadikan mereka sebagai kader yang akan meneruskan sistem budidaya ini kepada siswa dan kepada penduduk sekitar. Secara ekonomi, penduduk sekitar yang memiliki pendapatan di bawah rata - rata dapat turut belajar cara penanaman dengan hidroponik untuk kemudian berusaha mempraktekkannya dan menjual produk yang dihasilkan. Produk 
dapat berupa tanaman hias dalam botol bekas berisi popok bekas ataupun produk dari tanaman yang telah dibudidayakan dengan sistem hidroponik. Tanaman hias yang ditanam dapat berupa keladi hias, sedangkan produk tanaman dapat berupa cabe.

Perumusan masalah yang terdefinisi dari TK Wiji Kelurahan Tegalrejo Pekalongan adalah bagaimana pendidikan karakter siswa terkait preservasi lingkungan dapat berkembang, dengan adanya masalah sampah popok disposable yang susah diolah atau dipecah dalam senyawa lain dan bagaimana memanfaatkan sampah popok sebagai media tanam teknologi hidroponik?

\section{METODE PENELITIAN}

TK Wiji Kelurahan Tegalrejo Kota Pekalongan akan dijadikan tempat penelitian tentang bagaimana pendidikan karakter siswa terkait preservasi lingkungan dapat berkembang, dengan adanya masalah sampah popok disposable yang susah diolah atau dipecah dalam senyawa lain dan bagaimana memanfaatkan sampah popok sebagai media tanam teknologi hidroponik. Guru akan dilibatkan dalam kegiatan sebagai sasaran penerima pendidikan teknologi. Selanjutnya guru wajib mengajarkan hasil kegiatan ini kepada peserta didik dalam bentuk metode pembelajaran juga kepada masyarakat sekitar agar mau menerapkan teknologi hidroponik untuk menambah penghasilan keluarga.

Pemecahan masalah yang ditawarkan dalam kasus ini adalah; Keseluruhan tahapan pelaksanaan dilaksanakan dengan metode secara proaktif berupa komunikasi dua arah yang berlangsung secara berkesinambungan sehingga permasalahan dapat ditemukan secara jelas begitu juga dengan solusi yang diberikan. Partisipasi guru TK Wiji adalah sebagai sebagai subjek pelatihan dan diskusi, maksudnya mereka akan berperan aktif dalam kegiatan penelitian dalam rangka penerapan hasil diskusi. Selain itu, mitra juga berperan sebagai agen dan mediator penyambung lidah yang akan meneruskan apa yang mereka dapat dari penelitian kepada siswa dan masyarakat sekitar.

\section{HASIL DAN PEMBAHASAN}

Kegiatan ini dilaksanakan di 2 tahapan pembahasan dan simulasi, yaitu diskusi pembuatan campuran pupuk organik berbahan limbah popok sebagai tahap pertama dan 
diskusi pembuatan hiasan hidrogel dari limbah popok sebagai tahap kedua. Setelah kedua tahapan dapat diikuti peserta dengan baik, maka selanjutnya dilakukan pendampingan terkait improvisasi pendidikan karakter peduli lingkungan oleh guru terhadap siswa didik dengan sarana belajar pemanfaatan limbah popok.

Tahap pertama yaitu diskusi pembuatan campuran pupuk organik berbahan limbah popok telah dilaksanakan dan diikuti oleh 5 orang guru TK Wiji Pekalongan. Diskusi diawali dengan evaluasi pemahaman peserta terkait teknologi hidroponik. Evaluasi diberikan dalam bentuk pertanyaan terbuka yaitu "1) Apakah yang Anda ketahui tentang teknologi hidroponik?, 2) Apakah Anda pernah menerapkan kultivasi hidroponik?, 3) Apakah Anda pernah mendengar aplikasi hidroponik dengan menggunakan media popok bekas?”. Jawaban yang diberikan oleh guru selaku peserta pada pertanyaan pertama berkisar tidak jauh dari bahwa "teknologi hidroponik adalah teknologi menanam dengan air", jawaban untuk pertanyaan kedua terdiri dari "belum pernah" oleh 3 orang dan "pernah" oleh 2 orang, sedangkan jawaban untuk pertanyaan ketiga berkisar "belum pernah".

Pada jawaban pertanyaan pertama, tampak bahwa guru belum begitu menguasai konsep hidroponik. Guru menganggap hidroponik hanyalah penanaman dengan air, sementara sebenarnya hidroponik dapat digunakan untuk menjelaskan kultivasi dengan menggunakan berbagai media asalkan bukan tanah dan tetap mengenal defenisi media yang dapat "memegang" air, sehingga suplai air dapat secara simultan menjadi pasokan bagi pertumbuhan tanaman. Pada jawaban yang kedua, terlihat bahwa hidroponik bukan merupakan kultivasi umum yang dilaksanakan oleh guru, hal ini dimungkinkan karena lingkungan sekolah adalah lingkungan pantai, sehingga konsep bercocok tanam jarang dilakukan, termasuk didalamnya kultivasi hidroponik. Warga lingkungan pantai lebih mengandalkan hidup mereka dari aktivitas di laut, seperti menjadi nelayan ataupun pekerja ikan asin. Hal yang berbeda dengan warga di lingkungan dataran tinggi yang umumnya mengandalkan hidup dari bercocok tanam, sehingga budaya kultivasi tanaman bukan lagi hal yang asing bagi mereka. Pertanyaan ketiga merupakan titik poin dimana kegiatan ini menjadi hal yang sangat bermanfaat bagi guru. Dengan belum pernah diketahuinya penggunaan limbah popok sebagai media hidroponik, maka pemateri dapat memberikan paparan materi seluas - luasnya terkait hidroponik dan limbah popok. 
Pada tahap pertama, diskusi dilanjutkan dengan pembuatan media tanam dari popok bekas. Pembuatan media tanam dimulai dengan menggunting popok bekas kering, lalu diambil bagian kapas dan gelnya, sedangkan kain pelapisnya dibuang. Isi popok tersebut dicampurkan dengan arang sekam dengan perbandingan $1: 1$ dan diperam selama 1 bulan sebagaimana tampak pada gambar 5.

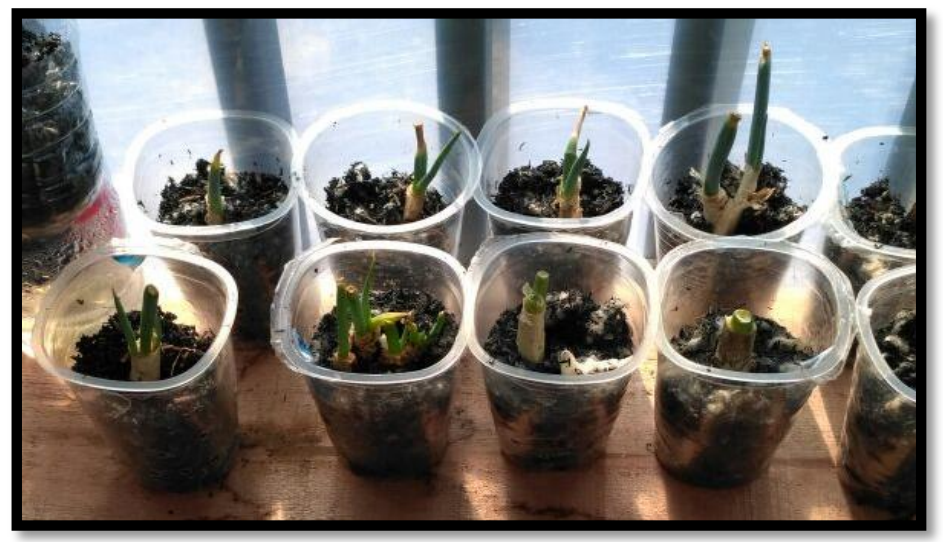

Gambar 5. Media Hidroponik yang dibuat dengan campuran popok bekas

Pada akhir pertemuan tahap pertama dilakuan evaluasi keterampilan guru setelah mengikuti kegiatan. Evaluator bertugas menilai keterampilan dalam 4 skala, yaitu skala sangat terampil, terampil, kurang terampil dan tidak terampil. Pada gambar 6 tampak bahwa 0 peserta yang sama sekali tidak terampil dalam menerapkan pengetahuan yang diperoleh, umumnya peserta sangat terampil dan terampil dalam menerapkan hidroponik sebagai medium teknologi hidroponik.

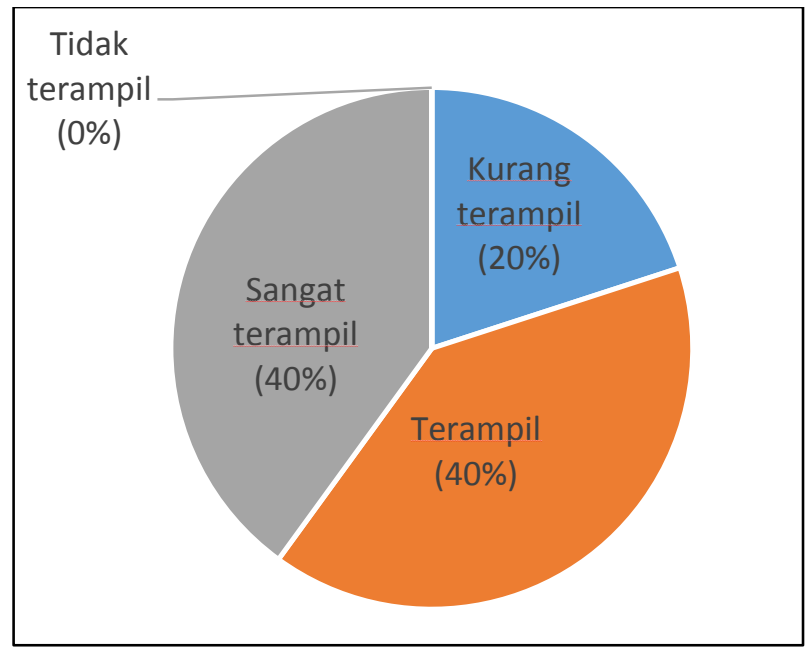

Gambar 6. Hasil evaluasi keterampilan guru dalam menggunakan popok bekas untuk pembuatan media hidroponik 
Pertemuan berikutnya dilaksanakan untuk memenuhi tahap kedua, berupa diskusi pembuatan hiasan hidrogel dari limbah popok. Pemberian materi diskusi diawali dengan penjelasan cara pembuatan hiasan hidrogel yaitu popok bekas basah digunting dan diambil bagian gelnya, selanjutnya isi popok tersebut direndam dalam air dengan perbandingan $1: 1$ dan diberi pewarna sebagaimana terdapat pada gambar 7. Terakhir, campuran diberi tambahan pupuk hidroponik dengan komposisi sesuai instruksi produsen pupuk. Pada pertemuan kedua evaluasi pemahaman terdiri dari pertanyaan "1) Apakah Anda mengetahui tentang hidroponik dengan menggunakan gel?" dengan kisaran jawaban: "Iya, mengetahui" serta pertanyaan "2) Apakah Anda tahu bahwa materi gel hidroponik sama dengan gel pengisi diapers?" dengan kisaran jawaban: "Belum tahu". Jawaban kedua menunjukkan bahwa kegiatan diskusi pembuatan media hidroponik dengan gel dari popok bekas adalah sangat bermanfaat untuk dilakukan.

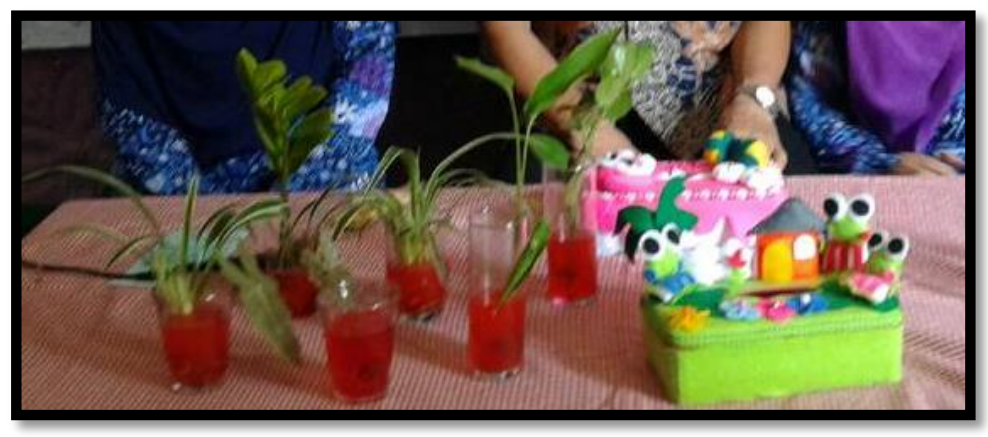

Gambar 7. Hiasan hidrogel dari limbah popok

Pada akhir pertemuan tahap kedua juga dilakuan evaluasi keterampilan guru setelah mengikuti kegiatan. Gambar 8 merupakan ringkasan hasil evaluasi yang menunjukkan bahwa tidak ada peserta yang tidak terampil atau kurang terampil dalam menerapkan pengetahuan yang diperoleh, umumnya peserta sangat terampil dan terampil dalam memanfaatkan gel dari popok bekas sebagai media hidroponik. 


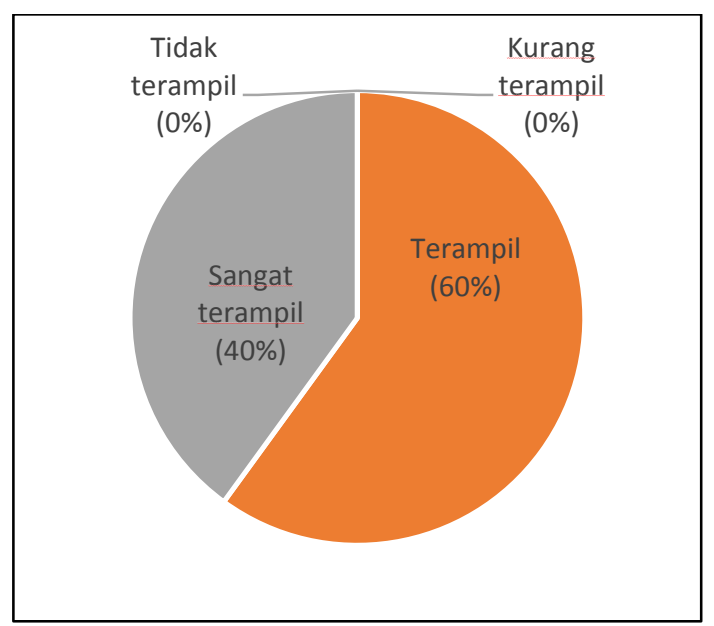

Gambar 8. Hasil evaluasi keterampilan guru dalam menggunakan gel dari popok bekas sebagai media hidroponik

Pada kedua tahapan kegiatan, sepanjang kegiatan guru didorong untuk aktif bertanya apabila ada hal yang kurang dimengerti, seperti "Apakah popok bekas yang digunakan boleh popok yang masih basah?” yang kemudian mediator jawab bahwa jika popok masih basah maka akan susah memisahkan antara isi popok dengan pembungkusnya, lalu “Apakah campuran arang sekam dan popok bekas bisa langsung digunakan?" yang kemudian mediator jawab bahwa jika langsung digunakan maka akan timbul "panas" oleh fermentasi air kencing yang ada dipopok bekas, serta "Apakah arang sekam boleh diganti dengan sekam biasa?", yang dijawab oleh mediator bahwa jika sekam biasa maka proses pengkomposan belum sempurna sehingga sistem pengkomposan lanjutan pada saat dicampur dengan popok bekas akan membuat media belum siap untuk ditanami tanaman dan akan mengganggu pertumbuhan tanaman itu sendiri. Nilai karakter tidak mudah menyerah, kemampuan kerjasama dan disiplin untuk membuang sampah pada tempatnya telah mengalami peningkatan hal tersebut dilihat dari jumlah skor hasil pengamatan setelah kegiatan lebih besar dari pada sebelum kegiatan.

\section{SIMPULAN}

Teknologi hidroponik dengan memanfaatkan sampah popok berhasil membuat tanaman tumbuh dengan baik dan dapat digunakan sebagai sarana pendidikan peduli terhadap lingkungan dan peningkatan nilai karakter tidak mudah menyerah, kemampuan kerjasama, disiplin dan rasa ingin tahu (berani bertanya) siswa TK Wiji Kelurahan Tegalrejo Kota Pekalongan. 


\section{DAFTAR PUSTAKA}

Anonim (2005). Standar Prosedur Operasional TK WIJI KOTA PEKALONGAN.

Abd El-Rehim HA, Hegazy ESA, Abd ElMohdy HL, (2004), Radiation synthesis of hydrogels to enhance sandy soils water retention and increase plant performance, J Appl Polym Sci, 93, 1360- 1371.

Buchholz FL, Graham AT, Modern Superabsorbent Polymer Technology, WileyVCH, New York, Ch 1-7, 1998

Colón, J., Mestre-Montserrat, M., Puig-Ventosa, I., \& Sánchez, A. (2013). Performance of compostable baby used diapers in the composting process with the organic fraction of municipal solid waste. Waste management, 33(5), 1097-1103.

Dey, S., Kenneally, D., Odio, M., \& Hatzopoulos, I. (2016). Modern diaper performance: construction, materials, and safety review. International Journal of Dermatology, 55(S1), 18-20.

Dyer D. Seven Decades of Disposable Diapers: A record of continuous innovation and expanding benefit. Brussels: EDANA, 2005.

Jon Schneller, A., Schofield, C. A., Frank, J., Hollister, E., \& Mamuszka, L. (2015). A Case Study of Indoor Garden-Based Learning With Hydroponics and Aquaponics: Evaluating Pro-Environmental Knowledge, Perception, and Behavior Change. Applied Environmental Education \& Communication, 14(4), 256-265.

Nhut, D.T., Nguyen, N. H., dan Thuy, D. T. T. (2006). A Novel in Vitro Hydroponic Culture System for Potato (Solanum tuberosum L.) Microtuber Production, Scientia Horticulturae, 110, 230-234.

Rahayu, Y. (2016). Perancangan Komunikasi Visual Kampanye Penggunaan Cloth Diaper Sebagai Solusi Popok Ramah Lingkungan (Doctoral dissertation, Institut Seni Indonesia Yogyakarta). 